\title{
APPLYING A TRAINING PROGRAM FOR DEVELOPING CONTEMPORARY SKILLS AMONG SOCIAL GROUP WORKERS IN THE SCHOOL FIELD
}

Hendawy A. Hassan

Associate Professor at the Faculty of Social Work,

Beni Suef University 


\section{APPLYING A TRAINING PROGRAM FOR DEVELOPING CONTEMPORARY SKILLS AMONG SOCIAL GROUP WORKERS IN THE SCHOOL FIELD}

\section{Hendawy A. Hassan}

Associate Professor at the Faculty of Social Work, Beni Suef University

\section{ABSTRACT:}

This research is aimed to develop contemporary skills among school social workers through training, to improve their performance amid emerging problems. The skills chosen were namely: managing differences, working through challenges and difficult situations, providing creative solutions to problems, and using modern technology. The researcher adopted a quasi-experimental approach in conducting a training program targeting thirty-eight social workers in preparatory and secondary schools in Helwan. Trainees received thirty hours of training, using diverse training methods, followed by three months of field support to ensure smooth application of skills. The researcher used a tailored scale for measuring skills development among social workers. The program succeeded in reaching its objective. It is now applicable to practitioners all over Egypt.

\section{KEYWORDS:}

Training program - development - contemporary skills - social group workers.

\section{INTRODUCTION:}

The educational field is considered one of the most important areas of interest among social workers as it encompasses a large number of community members, amounting to several millions, and includes multiple institutions that cover various age groups. In addition, the educational field plays an important role in preparing individuals for their future lives (Khater, Kishk, 2007, p.2).

The importance of this research is derived from the importance of the educational field in relation to social work. Group work historically has been and continues to be a method used by school social workers. (Letendre, 2009, p. 595) 
Social group work has been practiced in the school arena in Egypt for sixty-five years starting with a decree from Professor Taha Hussein, the famous writer, then the Minister of Education (El Guindy, 2005, p. 283).

Despite the long history of social group work practice in the school field in Egypt, social workers continue to face many problems in this field. Saad's study indicated the presence of numerous obstacles such as increased workload, low number of social workers, and the lack of resources (Saad, 1992).

In his study, Mostapha pointed to the lack of continuing education and training for social workers in the school field and incompatibility of the technical social work practices to the contemporary changes taking place in the field (Mostapha, 2000).

According to a study implemented by the General Department of Social Education in Egypt, the department responsible for supervising social work, these obstacles continued into the twenty first century (El Sherif, 2009).

The occurrence of the Arab Spring events, including the 25 January and the 30 June revolutions in Egypt, and their ensuing complications, have naturally affected the school community, being an integral part of the community at large. Violence spread between students, sharp arguments triggered by differences in political views occurred, and lack of respect for elders increased among students. These effects on the school community requires the concerted efforts of all professions, especially social work, as it encompasses various approaches and methods, and follows closely the local, regional, and international changes. Social work uses research and studies, and disseminates the knowledge and skills needed to overcome the obstacles facing the practice (Hassan, 2014, p. 1483).

Many challenges face social group work practice in the school field, which requires the application of contemporary skills in the professional practice with groups. Contemporary skills demonstrate the practitioner's ability to address multi-phenomenal problems and conflict inducing situations (Trevithick, 2005, p.65).

The researcher had conducted a previous introductory study on the extent to which school social workers apply contemporary skills. That study was implemented with a sample of 118 social group workers in preparatory and secondary schools under the Department of Education in Helwan, Cairo. The study included ten contemporary 
skills. Those were time management, managing differences, conflict management, working through challenges, analytical thinking, reducing resistance to change, using modern technology, providing creative solutions to problems, team work, and community participation. The study found that $35.6 \%$ of the respondents did not possess any information on applying contemporary skills in professional practice, and $38.9 \%$ did not have a specific understanding of contemporary skills, while only $22.5 \%$ of respondents used contemporary skills to some extent. Results indicated that none of the social workers in Helwan Department of Education received training in this field, and that a need exists for developing the social workers' knowledge and ability to apply specific skills, namely using modern technology, working through challenges and difficult situations, providing creative solutions to problems, and managing differences (Hassan, 2014).

Results also indicated that the level of professional performance among social workers is only linked to the knowledge they acquired during their studies. This reflects a deficiency in the professional practice resulting from the relative discontinuation of knowledge gain and the failure to pursue what is new in the social work profession. Accordingly, social workers do not possess some of the critical skills and knowledge related to modern and contemporary trends in professional practice. Therefore, it is necessary to conduct ongoing training to improve the social workers' performance (Ben Youssef, 2014, 4785). Thus, post-graduate training is essential for ensuring the development of knowledge and skills among social workers through the provision of various training programs.

The training program comprises both informational content and planned practical exercises, where several methods are used, such as lectures, workshops, role-plays, and visits. In this research, the training program had the specific function of developing the skills of the target group. In this context, development means providing social workers with new information on contemporary skills, improving the knowledge they already possessed, improving their application of said skills through training and practice, and improving their abilities to overcome difficulties during application.

Several studies have pointed to the importance and effectiveness of training in refining and developing the skills of social 
workers and providing them with the theoretical information they need for practice (see Hassan, 2010).

The current research focused on using the training program as a tool for developing contemporary skills among social group workers in the school field, specifically centering on four skills.

The first skill is managing differences. By applying this skill, the social group workers respect the cultural differences between group members that could hinder communication. The social workers avoid discrimination or preference towards one of the cultures, and use a common language that could bridge the gap between differences (Nakamura, 2000, p. 171). Through this skill, the social group workers also refine their own personal values while reviewing their group work values in relation to ideas, emotions, and ideal group behaviors to ensure their consistency. Social workers learn to accept differences, and choose the most suitable methods for managing them, while letting the group choose a leader who could contain those differences and adopt activities that bring members closer (DeluciaWaack \& Donigian, 2004, pp. 27-28).

The second skill is working through challenges and difficult situations, which may occur when group members engage in spreading rumors, narcissism, and pressuring obstructive group members. Through this skill, social workers seek to strengthen the relations between members inside the group through spreading the culture of respect and acceptance, nourishing integration and depth in relationships, encouraging confrontation where misunderstandings occur, and performing continuous analysis of relationships for developing them (Gamble \& Bamble, 2002, pp. 230 - 235).

In addition, this skill allows social workers to reformulate obscure situations, and to clarify negative situations that could hinder the members' ability to see the whole picture. Good understanding of different situations help provide opportunities for response and clarifications. Social workers in this case have to maintain calmness, watch behaviors, choose words carefully, manage decisions on when to agree with or contradict the targeted persons through verbal and nonverbal communication, as well as neutralize the other person's 
behavior if necessary to ensure their focus on listening and understanding the situation (Nicole, 2008, pp. 4-7).

The third skill is providing creative solutions to problems. This skill requires the social group worker to be creative and come up with innovative and new ideas. It also targets performance improvement, increased productivity, efficiency, swiftness, commitment, flexibility, and quality performance. (Sefertzi, 2000, pp. $2-5)$.

When searching for creative solutions social workers should focus on the future while examining all details and viewing the problems from different angles and perspectives. It also allows them to seek several traditional and nontraditional ideas to provide efficient solutions, focusing on the strength of ideas and investing in talents and potentials for transforming ideas into practical solutions, and taking all factors into consideration (Lsaken, 2010, p.21).

The fourth skill is using modern technology. The importance of this skill lies in the diversity of users of social media like Facebook, Twitter, and Instagram, among others. Social media is popular among children and teenagers, who prefer intensive interaction in the virtual world rather than human interaction within actual groups or institutions. This requires the social workers to be more active in technological communication with students and to increase their participation in virtual groups set up by students on Facebook. Using this skill, social workers could raise the students' awareness on the importance of exercising caution in the virtual world and promote using time positively and efficiently. This is in addition to raising awareness on the importance of parental supervision, and guiding students towards positive virtual interaction (Aly, 2013, pp. 312 -313).

Several previous studies addressed issues and topics related to the current research. Abdel Gelil's study indicated that training programs for social workers in the school field are standard programs focusing on the skills of team building, managing group discussions, and recording, which do not address the actual needs of social workers (Abdel Gelil, 1997). Abdel Gelil's study directed the attention of the current research towards ensuring that training programs address the actual needs of practitioners and incorporate new issues and topics.

In a study by "Klau", the author concluded that graduate social work students would benefit from the inclusion of a workshop 
experience or similar exercises in creative problem solving in the social work curricula. An analysis of gains in the various problemsolving ability areas by demographic factors indicated that the creative problem-solving experience was equally effective for first and second year graduate students and for students of various ages and socioeconomy strata. The author further concluded that greater emphasis in the workshops should be placed on the development of effective implementation strategies (Klau ,1981).

The difference between Klau's study and the current research mainly lies in Klau's focus on students of social work, while the current research focused on practitioners. Findings from the study of Chernack on "The Relationship of Knowledge, Skill and Confidence in Hospital Social Work Practice" demonstrate significant associations between knowledge and confidence, and between skill and confidence. The analysis also found associations between confidence and experience, between individual supervision and knowledge, and between knowledge and experience (Chernack, 2001). Chernack's study focused on the medical field, while the current research focused on the school field.

Silver conducted a study on "Barriers for Social Workers in the Use of Practice Skills in School Settings, and the Relationship between These Barriers and Intervention Skills with Children". Results from this study demonstrate that increase in caseload size; better office space, good teacher relationships, and parental involvement have a positive impact in the social worker's use of intervention skills. Interdisciplinary teem-meeting participation and acceptance showed no effect on the use of such skills (Silver, 2003).

Silver's study differed from the current research in skills and target groups, where the current research focused on school groups rather than individual cases.

In a study by Calitz on "A Social Work Training Programme for Caregivers of Infants in San Bernardino Country, California", the researcher concluded that the research problem of quality caretaking of an infant is addressed through internalizing theoretical knowledge and practical skills during the training program. The caregivers are able to care optimally for an infant at home. They are equipped with play techniques and mediums, which are adapted within the Gestalt approach and supported by relevant aids. The caregiver is able to stimulate the infants' developmental needs and tasks in this 
developmental phase (Calitz, 2005). Calitz's study established the importance of the caregivers' acquisition of knowledge and skills, which was confirmed through the current research.

White indicated in his study that social workers must be culturally competent to address the consequences of diversity in ethnic backgrounds, race, class, sexual orientation and culture in a pluralistic, multi-cultural society with its clients. Cultural competency is a major emphasis of social work practice that is encouraged by National Association of Social Workers (NASW) and the Council of Social Work Education (CSWE) (White, 2005). The current research agreed with White's study on the issue on cultural diversity, which was addressed in managing differences skill.

In another study by Caso Morris on "School Social Workers' Use of Computer Technology to Expand School-Based Mental Health Services: An Exploratory Study", the findings suggest that some innovative school social workers appear to be in the early stages of using computers to expand access to school-based health services. The data demonstrate that school social workers are presented with a complex array of issues and obstacles as they attempt to take advantage of the benefits of technology in a school setting. This research reinforces that there are advantages to paying detailed attention to the transfer process of computer technology into the culture of school social work (Caso-Morris, 2006). Therefore, that study is considered an important guide for the current research, which focused on training practitioners to use modern technology while working with groups.

Findings from Leinster's study on "Identifying the Education and Training Needs of Social Work Manager in Ireland" clearly show that social work managers do participate in post qualifying education and training, primarily to enhance their existing social work skills rather than developing their management skills (Leinster, 2009). The researcher benefited from this study through assessing the training needs of social workers before designing and implementing the training program.

Truong published a study on "Developing Best Practice Skills for Beginning Social Work Clinicians through Personal Experiences and Research". This research project explores best practice skills recommended for developing social workers through demonstration 
from personal experiences and research from scholarly literature. Accompanied by personal stories, an analysis of preparatory skills and basic communication skills are discussed for beginning social workers to assist clients more effectively, The skills and personal experiences help contribute to maintaining social work practice through building personal self-awareness, clinical growth, preserving therapeutic relationships with clients (Truong, 2013).

Truong's study relied on developing practical skills through personal experience and research, while the current research relied on training, with its varying methods, to develop contemporary skills.

Ibrahim's study on "Evaluating the Role of the Academic Supervisor in Developing Field Training Students' Acquisition of Contemporary Skills in Group Work" focused on developing the skills of decision making, time managed, and using information technology. The study found that the academic supervisor has a role in providing field-training students with contemporary skills (Ibrahim, 2014). Ibrahim's study differed from the current study in terms of target groups and skills chosen, as well as the nature of the study and its methodology.

Findings from Sevilla's study on "Essential Leadership Characteristics, Skills, and Knowledge of Future Social Work Community-Based Human Service Nonprofit Leaders: A Delphi Study" indicated that specific characteristics, skills and areas of knowledge are essential for future social work leaders to successfully sustain community - based nonprofits in the next 15 years: communication, professionalism, credibility, business skills and fiscal knowledge. Future social work leaders must understand the dynamic communities they serve and know how to address and manage change using sound theory in decision making in the ever - changing nonprofit environment (Sevilla, 2014). Sevilla's study provided guidance for the current research, which focused on developing the skills of social workers, considering them future leaders that have to build qualifications for managing the school social work process.

\section{Research Goals :}

The main goal of the research was measuring the effectiveness of a training program for developing contemporary skills among social group workers in the school field. The focus was on four main skills, namely: managing differences, working through challenges and 
difficult situations, providing creative solutions to problems, and using modern technology.

The researcher had also defined the procedural concepts of the research as follows:

Contemporary Skills: These are new skills that emerged to address transpiring challenges; different skills than those already practiced by social workers in group-work; innovative skills for working groups; and skills that deal with changes and contemporary issues.

- Skills for Managing Differences: It is the ability of the social group worker to contain differences and achieve integration and co-existence. It is the ability to support the group in adopting standards for containing differences, refining the group values, and encouraging commitment to said values. It is also the social worker's ability to help the group accept the other and respect cultural diversity, and the ability to diversify the group's programs to embrace cultural and religious differences, and increase attraction to the group.

- Skills for Working through Challenges and Difficult Situations: It is the ability of the social group workers to predict obscure situations, and their ability to view the causes of the problem holistically. It is the ability to develop suitable plans to deal with different situations, to strengthen relationships, and to reduce the negative effects of difficult situations, as well as the ability to clarify situations and understand their complexities, while discussing them in detail with the group. It is also the social group worker's ability to address situations through reviewing the roles of members and leaders to create a feeling of equity within the group.

- Skills for Providing Creative Solutions to Problems: It is the social worker's ability to analyze problems and create ideas and various solutions. It is the ability to use innovative methods in solving problems, and to ensure soft interference in the different parts of the problem, as well as the ability to follow untraditional methods in addressing problems. It is also the ability of the social group worker to provide a holistic solution to the problem and to address its obscure causes. 
- Skills for Using Modern Technology: It is the ability of the social group workers' to use modern technology methods and to participate in electronic groups. It is the ability for providing guidance and practicing positive interaction. It is also the ability to use technology for achieving the group's tasks and for presenting the group's achievements in the virtual world.

\section{METHOD:}

\section{Hypotheses:}

Primary hypothesis: There are statistically significant differences between the mean score of social workers on the contemporary skills scale before and after the program that is higher in post program measurement.

In addition, the research had four sub-hypotheses as follows:

- There are statistically significant differences between the mean score of social workers on the first dimension, related to managing differences, before and after the training program that is higher in post program measurement.

- There are statistically significant differences between the mean score of social workers on the second dimension, related to working through challenges, before and after the training program that is higher in post program measurement.

- There are statistically significant differences between the mean score of social workers on the third dimension, related to the providing creative solutions to problems, before and after the training program that is higher in post program measurement.

- There are statistically significant differences between the mean score of social workers on the fourth dimension, related to using modern technology, before and after the training program that is higher in post program measurement.

\section{Sample and intervention}

A purposive sample of thirty-eight social group workers in preparatory and secondary schools, from a total of one hundred and eighteen social workers in the department were selected for the study. The sample included only social workers who met specific conditions. They had all been part of the sample chosen in the researcher's previous research implemented in 2014, and had not been applying contemporary skills. They had also shown interest in joining the training program; in addition to being nominated to join by the 
professional supervision responsible, which indicated their ability to participate and interact in the program.

The majority of social workers were female, $92.10 \%$. Preparatory and secondary school representations were $48 \%$ and $52 \%$ of the sample successively. The research was implemented in Helwan area, where the first descriptive research mentioned by the researcher in the introduction, had been previously implemented. The sample was homogeneous, as all participants were group workers, from one geographic area, with a similar number of years of experience. This was reflected on their positive interaction during the program. The research was completed in two phases starting from 26/1/2015 to $7 / 5 / 2015$. After the researcher acquired the necessary security and administrative permissions, the first phase was implemented over 30 training hours during the period from $6 / 1 / 2015$ to $1 / 2 / 2015$. This phase included the provision of theoretical information on contemporary skills, as well as workshops, discussions, brainstorming, and role-plays. The second phase was implemented from 8/2/2015 to $7 / 5 / 2015$, which is the second school semester. During this phase, the researcher conducted visits to the social workers applying the program in their schools for three months. The researcher used the visits to follow-up on the social workers, supporting them in overcoming the challenges that they faced in applying the acquired skills, and providing them with the needed guidance.

The research depended on the use of a measurement tool, a scale, for gathering data on the skill level of the sample before the implementation of the training program on $26 / 1 / 2015$, and after its completion on $7 / 5 / 2015$.

The researcher followed scientific steps in formulating the scale of contemporary skills, starting by identifying the main subject of the scale and its four dimensions. Those were chosen based on the results of the researcher's previous research, the social workers' needs, and the contemporary school problems indicated by the professional supervision responsible for the social workers. Such problems include violence, disagreements, lack of respect for others, rebellious attitude, and weak technological communication between students and social group workers.

The researcher prepared the scale statements through using available theoretical literature on contemporary skills and consulting with specialists in the field. The statements were then formulated as 
situational statements, where each represented a situation related to one of the skills. Each situation/statement contained three responses identifying the type of interference needed from the social worker, ranging between non-interference, negative interference, or skill related interference. Following are some examples of said statements:

- After forming the group, you discover unusual differences in views

a. You disregard it, as these differences will disappear through time.

b. You oblige group members not to display differences.

c. You think of activities and programs that embrace those differences and promote integration.

- When rumors spread within the group

a. You let the rumor complete its cycle and end on its own.

b. You search for the source of the rumor to be punished.

c. You review the group rules, values, and criteria and modify them.

- While solving emerging problems within the group

a. You resort to usual and tried solutions.

b. You resort to a disciplinary action to end the situation.

c. You resort to a quick innovative solution derived from your and the groups members' ideas.

- When the members request the formation of a group on Facebook

a. You depreciate it to avoid wasting time.

b. You refuse, fearing the effects of the internet on the group members.

c. You encourage them and supervise their use.

The researcher abided by the procedural concepts of the skills while formulating the situations and responses. To ensure face validity, the scale was presented to five specialized professors for assessment: Professor Dr. Nassif Fahmy, Professor Dr. Mohammed Bahaa, Professor Dr. Mohammed El Zarif, Assistant Professor Adel Musharraf, and Assistant Professor Ali Moussa. The scale was reviewed by the specialists mentioned to ensure its soundness in terms of language and correlation between subject and dimensions. This was followed by a final refinement and reformulation process until it 
reached its final form with 28 situational statements, seven for each skill. The highest score that a respondent could reach was 84 , with 56 as the medium score, and 28 as the least score on the scale as a whole. For each of the four dimensions, the highest score a respondent could reach in each was 21 , with a medium score of 14 , and the least score was 7.

The internal consistency of the scale was validated through finding correlations between the score of each dimension and the overall score of the scale after applying it on 10 respondents outside the sample. The results were as follows:

Table (1)

Correlation between the Score of Each Dimension and the Total Scale Score Using Pearson Correlation Coefficient $\mathbf{N}=\mathbf{1 0}$

\begin{tabular}{|l|r|}
\hline \multicolumn{1}{|c|}{ Scale Dimensions } & Value of R and Significance \\
\hline Managing differences skill & $0.823^{* *}$ \\
\hline $\begin{array}{l}\text { Working through challenges and } \\
\text { difficult situations skill }\end{array}$ & $0.871^{* *}$ \\
\hline $\begin{array}{l}\text { Providing creative solutions for } \\
\text { problems skill }\end{array}$ & $0.800^{* *}$ \\
\hline Using modern technology skill & $0.803^{* *}$ \\
\hline
\end{tabular}
** Significant at 0.01

To ensure the internal consistency reliability, the researcher used a test-retest method, where the scale was applied on 10 respondents, and then reapplied on the same respondents after fifteen days. The results of the two applications of the scale were compared using Pearson's correlation coefficient.

Results were as follows:

Table (2)

Comparison between the First and Second Application Using Pearson's Correlation Coefficient

$\mathrm{N}=10$

\begin{tabular}{|l|r|}
\hline \multicolumn{1}{|c|}{ Scale Dimensions } & Value of R and Significance \\
\hline Managing differences skill & $0.965^{* *}$ \\
\hline $\begin{array}{l}\text { Working through challenges and } \\
\text { difficult situations skill }\end{array}$ & $0.815^{* *}$ \\
\hline
\end{tabular}




\begin{tabular}{|l|r|}
\hline \multicolumn{1}{|c|}{ Scale Dimensions } & Value of R and Significance \\
\hline $\begin{array}{l}\text { Providing creative solutions for } \\
\text { problems skill }\end{array}$ & $0.804^{* *}$ \\
\hline Using modern technology skill & $0.935^{* *}$ \\
\hline The Scale as a whole & $0.973^{* *}$ \\
\hline
\end{tabular}

** Significant at 0.01

The results in the previous table show the consistency of the scale and its reliability for application. The researcher then prepared for and implemented the training program as follows.

\section{Training Program}

The researcher followed specific guidance in preparing, designing, and implementing the training program, using the "input, transformational processes, and outputs" approach, where the trainees were considered an open range that interacts with other ranges, affecting them and being affected by them. This approach depended on human resources, inputs (social workers, trainers, and researcher), material resources (the location and equipment, technological methods), time, and the governing rules, all as the inputs of the approach. The transformational processes were represented in the training methods used, the interaction, discussions, and field visits conducted by the researcher. As for outputs, they were represented in the social workers' acquisition of knowledge and information related to contemporary skills and the occurrence of change in favor of those skills.

The researcher followed several criteria while designing the training program. Those including identifying the training needs of social workers through a previous research. The researcher laid down the general framework of the program after reviewing theoretical literature and consulting with specialists in the area. This was followed by identifying available resources for implementing the program, in coordination with the Helwan Education Department Management, and agreeing on the suitable date for starting and implementing the program. The program was planned to start in September 2014 before the beginning of the school year. However, due to the delay in issuing the needed security permissions for implementation because of unfavorable conditions and unrest, the program started in 26/1/2015. 
The researcher decided on the relevant informational content to the skills targeted for development among practitioners, in coordination with specialized trainers and other persons assisting him in implementation. They also agreed on the suitable training methods.

The researcher used a number of training methods. This included lectures (for providing trainees with theoretical information on the four skills). Six lectures were implemented by the researcher, assisted by Professor Dr. Nassif Fahmy and Assistant Professor Aly Mousa of Helwan University. The lectures, two hours each, took place during the first stage of the training program, which focused on theoretical information. Each lecture was followed by a group discussion on the provided information, as well as workshops and role-plays to ensure the trainees interaction, practicing the application of skills, and playing out different situations with possible interferences from social workers. This stage continued for 30 training hours over a period of 6 days.

The second stage of the program started with the return of social workers in February 2015 after the completion of the first stage, which had taken place during the mid-year vacation. In this stage, the researcher organized monthly meetings with the trainees and conducted weekly visits to their schools. The researcher had conducted in total three meetings for all participants, and twenty-four visits to the trainees' workplaces in schools. During the meetings and visits, the researcher consulted with the trainees, discussed methods for applying the acquired skills and best ways for interference, responded to their questions, and identified difficulties and obstacles that they faced. These difficulties could be summarized in the limited time available for working with the students, the reoccurrence of problematic situations, high workload of social workers, the disregard that some students showed towards group work, and the lack of cooperation between colleagues in the school. The researcher provided social workers with advice on how to deal with those difficulties through mobilizing available resources, reviewing the program theoretical content, keeping contact with the researcher, and strengthening their relationships with the students through virtual communication. At the end of the school year, on 8/5/2015, the researcher applied a post-test on the 38 social workers that participated in the program, after which each trainee received a 
credited certificate from the Department management on completing the training program.

One of the main difficulties that the researcher faced in the program implementation was the delay in issuing the security permissions for starting the program, which led to postponing the program until the mid-year vacation. This is in addition to the lack of funding for training and the weak budget of the relevant governmental entity, which forced the researcher to implement the program at his own expense, including the costs of trainers, training, and participants.

\section{RESULTS}

Research results are described in the following table: 
Table (3)

Significance of Differences between the Pre and Post

Measurement

\begin{tabular}{||l|l|r|r|r|r|r||}
\hline Sr. & Dimensions & \multicolumn{2}{|c|}{ Pre-Testing } & \multicolumn{2}{|c|}{ Post-Testing } & \multicolumn{1}{|c||}{$\begin{array}{c}\text { Value of T } \\
\text { and its } \\
\text { Significance }\end{array}$} \\
\cline { 2 - 6 } A. & $\begin{array}{l}\text { Managing } \\
\text { differences } \\
\text { skill }\end{array}$ & 10.92 & 1.65 & 16.66 & 1.46 & $5.737^{* *}$ \\
\hline Beviation & $\begin{array}{l}\text { Working } \\
\text { Deviation } \\
\text { through } \\
\text { challenges } \\
\text { and difficult } \\
\text { situations } \\
\text { skill }\end{array}$ & 11 & 2.40 & 17.24 & 1.17 & $6.236^{* *}$ \\
\hline C. & $\begin{array}{l}\text { Providing } \\
\text { creative } \\
\text { solutions for } \\
\text { problems } \\
\text { skill }\end{array}$ & 11.16 & 1.81 & 16.87 & 1.36 & $5.710^{* *}$ \\
\hline D. & $\begin{array}{l}\text { Using } \\
\text { modern } \\
\text { technology } \\
\text { skill }\end{array}$ & 11.79 & 2.34 & 17.32 & 2.13 & $13.562^{* *}$ \\
\hline & All Skills & 4.92 & 4.55 & 68.26 & 4.20 & $35.597^{* * *}$ \\
\hline
\end{tabular}

** Significant at 0.01

The data in the previous table indicate that:

A. There were significant differences between the pre and post measurement of the skill level for the skill of managing differences among social workers in the school field; where the value of $\mathrm{T}=5.537$, significant at 0.01 . These differences were higher in post testing, where the pre-testing mean score for the skill was 10.92, while for the post-testing it was 16.66. This means that the training program led to developing the skill for managing differences among social workers in the school field, thus proving the validity of the first research subhypothesis.

B. There were significant differences between the pre and post measurement of the skill level for the skill of working through 
challenges and difficult situations among social workers in the school field; where the value of $\mathrm{T}=6.236$, significant at 0.01 . These differences were higher in post testing, where the pretesting mean score for the skill was 11, while for the posttesting it was 17.24. This means that the training program led to developing the skill for working through challenges and difficult situations among social workers in the school field, thus proving the validity of the second research subhypothesis.

C. There were significant differences between the pre and post measurement of the skill level for the skill of providing creative solutions to problems among social workers in the school field; where the value of $\mathrm{T}=5.710$, significant at 0.01 . These differences were higher in post testing, where the pretesting mean score for the skill was 11.16 , while for the posttesting it was 16.87 . This means that the training program led to developing the skill for providing creative solutions to problems among social workers in the school field, thus proving the validity of the third research sub-hypothesis.

D. There were significant differences between the pre and post measurement of the skill level for the skill of using modern technology among social workers in the school field; where the value of $T=13.562$, significant at 0.01 . These differences were higher in post testing, where the pre-testing mean score for the skill was 11.79, while for the post-testing it was 17.32. This means that the training program led to developing the skill for using modern technology among social workers in the school field, thus proving the validity of the fourth research sub-hypothesis.

There were significant differences between the pre and post measurement of the skill level for contemporary skills as a whole among social workers in the school field, where $\mathrm{T}=35.597$, significant at 0.01 . These differences were higher in post testing, where the pretesting mean score for contemporary skills was 44.92 , while for the post-testing it was 68.26. This means that the training program led to developing these contemporary skills among social group workers, thus proving the validity of the research main hypothesis.

\section{Discussion:}


The results supported the validity of the main and sub hypotheses of the research. These results, as well as the research outputs represented in the school social workers' acquisition of the needed knowledge for developing contemporary skills, are similar to results and recommendations of previous studies.

The training program provided social workers with new information and skills that suit contemporary changes as per Sellive's study recommendation that stressed the importance of knowledge and skills among future leaders of social work. Ibrahim's study found that the academic supervisor has an active role with students in field training. Results for this research also showed that the researcher had contributed to the development of contemporary skills among social workers through good preparation and seeking the help of specialists during the preparatory and implementation stages for the research. In addition, this research had benefited from Leinster's study recommendation for needs assessment. The researcher had followed this recommendation, identifying the needs of social workers in the area of contemporary skills in a previous research, and consulting with relevant professional supervision on field reality, problems, and contemporary skills that social workers need. The effect of the training needs assessment performed was clearly demonstrated during implementation of the training program through participants' responsiveness, commitment, and interaction, which led to the occurrence of change as presented in the post-testing.

The results and outputs of the research were also in line with the results of Coso Morris studies on computer usage, and White's recommendation on respecting cultural diversity. The research addressed both the skill of using modern technology and that of managing differences.

Results of the current research had also confirmed the findings from Catliz and Hassan's (2010) studies on the importance of training programs in the acquisition of knowledge and skills.

Despite the occurrence of change and the development of skills among practitioners, the difficulties that the social workers faced during their application of skills confirmed the findings of Silver's study on the effect of workload and work relationships on the social workers' application of skills. 
In addition, the current research agrees with Klau's study on the importance of using workshops for acquiring the skill. The researcher made use of this method, along with lectures, discussion, and role-plays, in all the skills.

The research results are considered novel to the social group work specialization as no experimental studies were implemented on these four skills. The previous studies were concerned, like the current research, with issues that need contemporary skills. However, the previous studies recommended finding solutions and promoting professional practices related to social group workers' use of technology, and the respect for cultural diversity. Thus, this research came as a practical implementation of previous study recommendations.

The research results confirm the realization of a number of outputs through the training program. Social workers developed the ability to manage differences. This was demonstrated in creating activities that bridge the gap between differences, adopting standards that encourage grouping and avoid discrimination, reviewing group values, supporting group members in following said values, and promoting the culture of coexistence and integrity.

Social workers developed the ability to work through challenges and difficult situations. Their ability was demonstrated in dealing professionally with members displaying obstructive behavior, overcoming rumors within the group, improving group information system, focusing on leadership roles during difficult situations, developing a holistic perspective of issues, and ensuring that ambiguous situations are clarified to all members.

Social workers developed the ability to provide creative solutions in terms of analyzing problems, reaching inventive solutions, and creating innovative ideas through brainstorming.

Finally, social workers also developed the ability to use modern technology. This was demonstrated in establishing Facebook accounts for presenting their achievements with the school groups.

The researcher confirmed those outputs through reviewing the post-measurement scale results, meetings with the social workers, and field visits, as well as through his own observation of the interactions that occurred during meetings and visits. The researcher attributes the success of the program, achieving the research objectives, and the realization of outputs to the good preparation of the program, the 
availability of resources, the diversity of training methods used, following up on the social workers' actual practice in schools, discussing difficulties, and responding to the trainees' queries during the two phases of the program. This is in addition to the participation of two specialists in the lectures during the first phase, whose experiences were added assets to the researcher's own experience and expertise in fieldwork.

\section{REFERENCES:}

Abdel Gelil, A. (1997), Adapting Social Workers Training Programs to Groups Social Work in the Educational Field in Cairo Governorate, MA Thesis, Cairo, Helwan University, Faculty of Social Work.

Abraham, M. Ahmed (2014). Evaluating the Role of the Academic Supervisor to Gaining Students Field Training the Modern Skills in Group Work, M.S.W., Cairo, Helwan University, Faculty of Social Work.

Aly, M. Abu El Maaty (2013), Modern Trends in Marketing Social Services and Information Technology, Alexandria, New University Office.

Ben Youssef, K. (2014), Training Needs of Social Workers for Achieving Professional Development, Cairo, Helwan University, Faculty of Social Work, Periodical for Studies in Social Work and Human Sciences, Issue 36, Part Four, April.

Calitz, M. Lusitano (2005), A Social Work Training Program for caregivers of infants in San Bernardino County, California. D. Ph. Il, South Africa, University of Pretoria.

Caso-Morris, D. (2006), School Social Workers' Use of Computer Technology to Expand School-Based Mental Health Services: An Exploratory Study, D.S.W., U.S.A., New York, Adelphi University, School of Social work.

Chernack, P. (2001), The Relationship of Knowledge, Skill, and Confidence in Hospital Social Work Practice. D.S.W, U.S.A., New York, Adelphi University, School of Social work.

DeLucia , W. et.al (2004), The Practice of Multicultural GroupBuffalo, Visions, and Perspectives from thefield, Australia, Thomson Brooks, Cole. 
El Guindy, K. Mohammed (2005), Group Social Work in the School Field, in Karam Mohammed El Guindy, Nadief Fahmy, Mohammed Bahaa El Din, Adel Meshref, Amal Badr, Professional Practice Processes on the Road to Group Social Work, pp. (281 - 314), Cairo, Zahraa El Sharq Queen.

El Sherif, A. El Desouky (2009), Obstacles and Problems Facing Workers in the School Field, Cairo, Higher Institute of Social Work, Seventh Scientific Conference.

Hassan, H. Abdellahy (2010), School Social group workers Usage of Contemporary Skills in the Social Work Professional Practice in Light of the Post 25 January and 30 June Challenges, Cairo, Helwan University, Faculty of Social Work, Studies in Social Work and Human Sciences Periodical, Issue 36, Part IV, April 2014.

Hassan, H. Abdellahy (2010), Training Program for Providing School Social Workers with the Skills for Using Scientific Models in Group Social Work, Cairo, Helwan University, Faculty of Social Work, Twenty Third International Scientific Conference.

Khater, A. Mostapha \& Kishk, M. Bahgat (2007), Professional Practice of Social Work in the Educational Field, Alexandria, New University Office, T2.

Klau, E. (1981). The Effect of a 3-Day Workshop in Creative Problem-Solving on Selected Aspects of Problems - Solving Ability in Graduate Students of Social Work, Ph.D. U.S.A, Maryland, University of Maryland.

Leinsler, J. (2009), Identifying the Education and Training of Social Work Managers, Ireland. M.LIH, Ireland National University of Galway.

Letendre, J. (2009), Working with Groups in Schools: Planning for and Working with Group Process. In Carol, R. Massat, C., Robert Shirley McDonald, John P. Flynn, School Social Work: Practice, Policy and Research (7 TH ed. pp. 595-638). Chicago: Lyceum Books.

Lsaksen, S. \& others (2010), Creativity Approaches to ProblemSolving: A Framework for Change, Creative Problem-Solving Group Buffalo, Pennsylvania State University.

Mostapha, M. Mahmoud (2000), Activating Professional Practice in Group Social Work in the School Field, Cairo, Helwan University, Faculty of Social Work, Thirteenth Scientific Conference. 
Nakamura, R. (2000), Healthy Class Management: Motivation, Communication, and Discipline, London, Wads Worth, Thomson Learning.

Nicole M. (2008). Skills for Working with Difficult People in Challenging Situation, MSW Optimal Solutions Consulting.

Saad M. EI Zareef (1992), Obstacles Hindering the School Social Worker from Supporting Student Activities, Cairo, Social Work Periodical, Egyptian Organization for Social Workers, Issue 34:35.

Sefertzi ,E. (2000).Creativity, Report Produced for the EC funded project, in no regio: innoregio Dissemination and Knowledge Management .

Sevilla, O. (2014), Essential Leadership Characteristics Skills, and Knowledge of Future Social Work Community-Based Nonprofit Human Service Leaders: Adelphi Study. Ed. D., U.S.A., California, University of La Verne.

Silver, J. Emile (2003). Barriers for Social Workers in the Use of Practice Skills in School Settings, Ph.D., U.S.A. New York, Columbia University.

Trevithick, Pamela (2005), Social Work Skills: A Practice and Book, New York, Open University Press, $2^{\text {nd }}$ ed.

Truong, A. (2013). Developing Best Practice Skills for Beginning Social Work Clinicians through Personal Experiences and Research, M.S.W, U.S.A., California State University.

White, K. Ray (2005), The Relationship between Social Work Practitioners' Attitudes, Beliefs, Skills, and Knowledge and Culturally Competent Direct Practice with African Descent Clients, Ph.D. U.S.A. Florida, Barry University, School of Social Work. 